\title{
Disinfection of Spacecraft Potable Water Systems by Passivation with Ionic Silver
}

\author{
Michele N. Birmele \\ Engineering Services Contract, Team QNA, Kennedy Space Center, Florida, 32899 \\ LaShelle E. McCoy ${ }^{2}$ \\ Engineering Services Contract, Team QNA, Kennedy Space Center, Florida, 32899 \\ and \\ Michael S. Roberts ${ }^{3}$ \\ Engineering Services Contract, Team QNA, Kennedy Space Center, Florida, 32899
}

\begin{abstract}
Microbial growth is common on wetted surfaces in spacecraft environmental control and life support systems despite the use of chemical and physical disinfection methods. Advanced control technologies are needed to limit microorganisms and increase the reliability of life support systems required for long-duration human missions. Silver ions and compounds are widely used as antimicrobial agents for medical applications and continue to be used as a residual biocide in some spacecraft water systems. The National Aeronautics and Space Administration (NASA) has identified silver fluoride for use in the potable water system on the next generation spacecraft. Due to ionic interactions between silver fluoride in solution and wetted metallic surfaces, ionic silver is rapidly depleted from solution and loses its antimicrobial efficacy over time. This report describes research to prolong the antimicrobial efficacy of ionic silver by maintaining its solubility. Three types of metal coupons (Inconel 718, Stainless Steel 316, and Titanium 6Al-4V) used in spacecraft potable water systems were exposed to either a continuous flow of water amended with $0.4 \mathrm{mg} / \mathrm{L}$ ionic silver fluoride or to a static, pre-treatment passivation in $50 \mathrm{mg} / \mathrm{L}$ ionic silver fluoride with or without a surface oxidation pre-treatment. Coupons were then challenged in a high-shear, CDC bioreactor (BioSurface Technologies) by exposure to six bacteria previously isolated from spacecraft potable water systems. Continuous exposure to $0.4 \mathrm{mg} / \mathrm{L}$ ionic silver over the course of 24 hours during the flow phase resulted in a $>7-\log$ reduction. The residual effect of a 24-hour passivation treatment in $50 \mathrm{mg} / \mathrm{L}$ of ionic silver resulted in a $>3-\log$ reduction, whereas a two-week treatment resulted in a $>4-\log$ reduction. Results indicate that $0.4 \mathrm{mg} / \mathrm{L}$ ionic silver is an effective biocide against many bacteria and that a prepassivation of metal surfaces with silver can provide additional microbial control.
\end{abstract}

\section{Nomenclature}

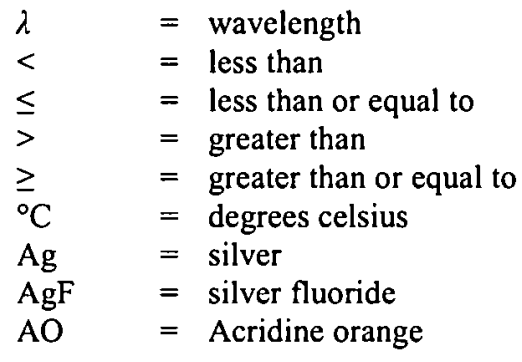

\footnotetext{
${ }^{1}$ Research Scientist, Engineering Services Contract, Team QNA, ESC-53.

${ }^{2}$ Research Scientist, Engineering Services Contract, Team QNA, ESC-53.

${ }^{3}$ Sustainable Systems Research Lead, Engineering Services Contract, Team QNA, ESC-53. 


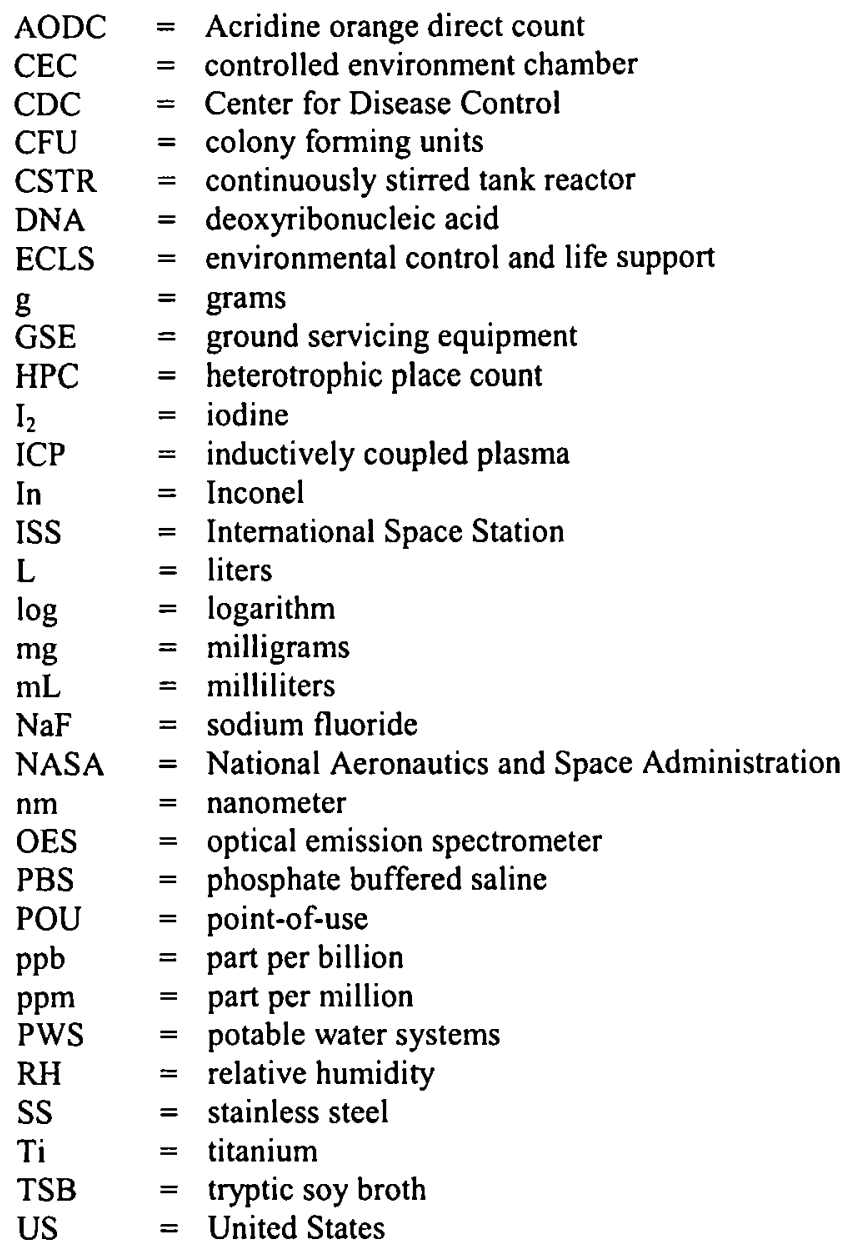

\section{Introduction and Background}

$\mathrm{T}$ The National Aeronautics and Space Administration (NASA) seeks to improve the performance of environmental control and life support (ECLS) systems necessary for the human exploration of space beyond low-Earth orbit. Technologies to improve microbial control are key to maintaining life support systems with minimum re-supply requirements and increased reliability during long duration missions. Water is the most critical life support element, representing $65 \%$ of the daily mass input for crew. ${ }^{10}, 11$ Per capita requirements for ingested water (4.5 L as liquids and water in food) represents twice the mass needed for food and oxygen combined. ${ }^{10,11}$ Advanced water recovery technologies are necessary to process urine, humidity condensate, and hygiene water to reduce water requirements for extended duration missions. ${ }^{10}$

Durable prevention of microbial growth, biofilm formation, and microbiologically induced corrosion in water distribution and storage systems for ECLS requires maintenance of a minimum concentration of biocide in solution and on the wetted surfaces of the system. Potable water systems may also require point-of-use (POU) sterilization capability as a secondary barrier to remove low-level bacterial contamination and to reduce the risk of source water back-contamination during mission operations. Since there is potential for depletion of biocide and the development of acquired microbial resistance to biocidal agents in water distribution systems over time, even sterile water that is treated with biocide and aseptically stored may support the growth and/or proliferation of microbial populations that can negatively impact crew health and promote materials corrosion.

Ionic silver has been identified as the primary residual biocide for future US spacecraft potable water systems. ${ }^{12}$ Ionic silver (or silver salts), colloidal silver, and silver-treated materials have a long history in hygiene applications and are widely used today in clinical, medical, and consumer material applications as antiseptic or microbiocidal agents. ${ }^{5,17}$ Silver (as silver nitrate), which is analogous to colloidal silver, is used extensively by the Russian space 
program, previously on MIR, and currently on the Russian side of the ISS. Although iodine $\left(I_{2}\right)$ is currently used on the shuttle for water purification, ionic silver was proposed by NASA as an antimicrobial additive for potable water purification in the shuttle program in 1974 (using silver chloride and silver bromide based filter cartridges). ${ }^{16}$ Iodine is, however, incompatible with biocidal silver systems such as those on the Russian side of ISS and must be removed by ion exchange during water transfer from the shuttle fuel cells to ISS. ${ }^{9}$ In addition, iodine imparts a reportedly bad taste to drinking water, accumulates in the thyroid, and can result in the halogenation of organic compounds resulting in the formation of cytotoxic chemicals posing a crew health risk during long-term missions. ${ }^{9}$ Unlike iodine, silver is an effective antimicrobial even at very low concentrations (i.e., $0.005 \mathrm{mg} \mathrm{Ag} \mathrm{per} \mathrm{L),} \mathrm{is}$ readily excreted from the body ( $90 \%$ clearance rate), and does not pose any known serious human health risks except at high intake levels (e.g., agrygia can occur, but only at very high and routine levels of silver intake). ${ }^{7}$

Silver ions $\left(\mathrm{Ag}^{+}\right.$or $\left.\mathrm{Ag}^{+}\right)$can inactivate and kill bacterial cells by multiple mechanisms: depression of nutrient uptake, inhibition of proton and electron transfer, inhibition of cell division, and interference with DNA replication by increasing stability of the DNA helix. ${ }^{14,16}$ Understanding the effects of antimicrobial agents, as alternatives to the use of iodine $\left(\mathrm{I}_{2}\right)$, and their interaction with wetted surfaces will enable better resource utilization on the CEV and improve crew safety by promoting inhibition of microbial growth and biofilm formation in spacecraft water systems. This report describes experimentation to evaluate technologies for delivery and maintenance of biologically effective, silver-based biocides that are safe for human consumption ( $\leq 0.40 \mathrm{ppm}$ ionic silver), stable in contact with wetted material surfaces in spacecraft potable water systems ( $\leq 230$ days), and capable of limiting bacterial growth in potable water $(<50 \mathrm{CFU} / \mathrm{mL})$. The objective was to characterize the biocidal efficacy of ionic silver spike at 50 $\mathrm{mg} / \mathrm{L} \mathrm{AgF}$ in presence of Inconel 718, Titanium 6Al-4V, and Stainless Steel 316 for pre-servicing loading of potable water into Ground Servicing Equipment (GSE) and vehicle Potable Water Systems (PWS). Once the baseline concentration of $\mathrm{Ag}^{+}$from the silver spike was established, then the goal was to characterize biocidal efficacy of ionic silver residual at $\leq 0.4 \mathrm{ppm} \mathrm{AgF}$ in presence of Inconel 718, Titanium 6Al-4V, and Stainless Steel 316 after ionic silver spike at $50 \mathrm{mg} / \mathrm{L} \mathrm{AgF}$.

\section{Materials and Methods}

\section{A. CDC Biofilm Reactor Experimentation}

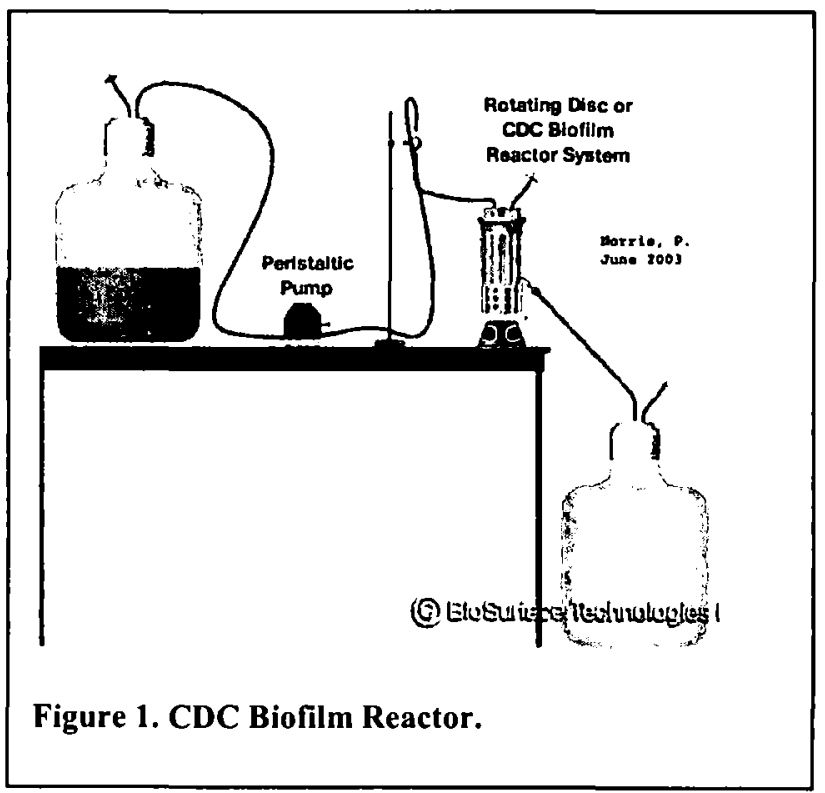

A CDC Biofilm Reactor (Fig. 1); BioSurface Technologies Inc, Bozeman, MT) was used to cultivate bacterial biofilms on nine replicate coupons in a defined high shear, hydraulic environment $(-125$ $\mathrm{rpm}$ to generate a Reynolds number >800) as described in ASTM E 2562-07 (Standard Test Method for Quantification of a Pseudomonas aeruginosa Biofilm Grown with High Shear and Continuous Flow Using CDC Biofilm Reactor).' The $\mathrm{CDC}$ reactor system including a digital magnetic stir plate and feed reservoirs were assembled and operated in a Controlled Environment Chamber (CEC) with control set points $\left(21^{\circ} \mathrm{C}, 50 \% \mathrm{RH}, 400\right.$ ppm $\mathrm{CO}_{2}$, and no lighting) and Tryptic Soy Broth (TSB) (BD, Difco, Franklin Lakes, NJ) culture medium per the standard method. Procedures for inoculation and operation of the CDC reactor for 24 hours in batch mode then 24 hours in CSTR (continuously stirred tank reactor) mode will follow those described in ASTM E 2562-07, but the method for sampling and analyzing the biofilm after reactor

operation will be modified from the standard method as described below.

After 24 hours of CDC reactor operation in CSTR mode, aliquots of process liquid (bulk fluid) and coupons will be removed to sample planktonic (non-adhering) and biofilm (attached growth) reactor populations, respectively. Metallic test articles ( $12.7 \times 1.5 \mathrm{~mm}$ coupons) will be removed from the CDC biofilm reactor after 48 hours with sterile forceps and rinsed with a sterile Phosphate Buffered Saline (PBS) (BD, Difco, Franklin Lakes, NJ) solution for 5 seconds on each side. After rinsing, each coupon was transferred to a sterile test tube containing $3 \mathrm{~mL}$ PBS for 
sonication ( $5 \times 1$-minute pulses with 1 -minute holds between treatments).

\section{B. Coupon Materials}

Coupon metal type was identified by mass, physical properties, and/or visualization under a dissecting microscope before experimentation. Inconel 718 was designated for baseline PWS Bellows tank material and each half inch square coupon had an average weight of $1.05 \pm 0.01$ grams $(\mathrm{g})$. Stainless steel 316 was designated for secondary Bellows tank material and each coupon averaged $1.19 \pm 0.02 \mathrm{~g}$. The third and final metal tested was Titanium $6 \mathrm{Al}-4 \mathrm{~V}$ which was designated for tubing material and each coupon averaged $0.56 \pm 0.01 \mathrm{~g}$.

\section{Analysis Methods}

Process liquid samples from the reactor and biofilms recovered from coupons after sonication treatment were prepared for Acridine Orange Direct Count (AODC) and spread plating onto R2A agar media for heterotrophic plate count (HPC). At least one coupon from each treatment was stained with Acridine Orange (AO) and microscopically imaged without the sonication treatment. In addition, the inoculum concentrations were also determined by viable plate counts on R2A media and by Acridine Orange Direct Count (AODC). A spectrophotometer was employed to rapidly measure optical density at $\lambda=590 \mathrm{~nm}$ to assist with the determination of cellular concentration. Heterotrophic plate counts (HPC) on R2 agar (R2A) were used to calculate $\mathrm{CFU} / \mathrm{mL}$ of culturable organisms. Acridine orange direct count (AODC) samples were fixed in $2 \%$ formalin was used to fluorescently stain live and dead cells. ${ }^{4,6}$ The stained cells were then analyzed and enumerated using a Zeiss Axioskop epi-fluorescent microscope. Thermo-Jarrell Ash IRIS Inductively Coupled Plasma Optical Emission Spectrometer (ICP-OES) was utilized for measuring ionic silver concentrations at wavelength 328.0 using EPA Method 200.7. Certified silver standard (CPI International, Santa Rosa, CA) was used to calibrate instrumentation. Instrumental settings used during analysis include 1150 Watts RF power, $1.5 \mathrm{lpm}$ auxiliary gas flow, $120 \mathrm{rpm}(2.22 \mathrm{~mL} / \mathrm{min}$.) analysis pump rate and flush pump rate using the ICAP light source.

\section{Silver Fluoride Preparation Protocol}

A silver fluoride/sodium fluoride concentrate solution was prepared consisting of:

$1100 \mathrm{mg} / \mathrm{L}$ silver |

$1100 \mathrm{mg} / \mathrm{L}$ fluoride $\mid->$ from pure $\mathrm{AgF}$ and $\mathrm{NaF}$ solids.

$1100 \mathrm{mg} / \mathrm{L}$ sodium |

For volume of concentrate $\left(\mathrm{V}_{\mathrm{c}}\right)$ in liters, the mass of $\mathrm{AgF}\left(\mathrm{M}_{\mathrm{AgF}}\right)$ and mass of $\mathrm{NaF}\left(\mathrm{M}_{\mathrm{NaF}}\right)$ required are:

$\mathrm{M}_{\mathrm{AgF}}=\left(\mathrm{V}_{\mathrm{c}} \times 1100 \times 126.86\right) / 1000 / 107.87=1.294 \mathrm{~V}_{\mathrm{c}}$

$\mathrm{M}_{\mathrm{NaF}}=\left(\mathrm{V}_{\mathrm{c}} \times 1100 \times 41.99\right) / 1000 / 22.99=2.009 \mathrm{~V}_{\mathrm{c}}$.

For $500 \mathrm{ml}(0.5 \mathrm{~L})$, the following quantities were dissolved in a $500 \mathrm{ml}$ volumetric flask using Nanopure water to fill to the mark:

For $\mathrm{V}_{\mathrm{C}}=0.5 \mathrm{~L}, \mathrm{M}_{\mathrm{AgF}}=0.647 \mathrm{~g}$

For $\mathrm{V}_{\mathrm{c}}=0.5 \mathrm{~L}, \mathrm{MNaF}=1.005 \mathrm{~g}$.

The flasks were covered in aluminum foil, with low room light conditions. The salts were weighted out and transferred to an Erlenmeyer flask containing $300 \mathrm{~mL}$ DI water. The salts were dissolved using a magnetic stirrer, for 1-2 hours. The solution was transferred to a $500 \mathrm{~mL}$ volumetric flask. The Erlenmeyer flask was rinsed thoroughly into a $500 \mathrm{~mL}$ volumetric flask. The volumetric flask was brought to the final volume with DI water, capped and shook vigorously for $2-5$ minutes. The stock solution was filter sterilized by vacuum filtration using a Nalgene disposable $500 \mathrm{~mL}$ capacity filter housing with a 0.2 micron cellulose nitrate filter (P/N 450-0020). The filtrate collection flask was capped, covered with foil, and stored in the dark.. The silver and sodium concentrations were verified that they were within $5 \%$ of the target concentration using ICP-OES.

\section{E. Coupon Passivation and Oxidation Protocols}

Prepared a 45\% Nitric Acid (Sigma-Aldrich, St. Louis, MO) passivation solution in acid-washed glassware. Prepared two acid-safe bins by rinsing with $45 \%$ nitric acid and deionized water. Added the prepared nitric acid solution to one bin, and filled the other bin with deionized water. Placed one type of metal coupon into a metal dishwashing bin, and placed into the nitric acid solution ensuring that all of the coupons are immersed. Let the coupons soak for 60 minutes with intermittent shaking (approximately every 5 minutes). Removed the bin from the nitric acid solution and placed into the deionized water. Shook to ensure thorough rinsing; replaced the water with fresh deionized water and rinsed two additional times. Placed the passivated, rinsed coupons onto an autoclaved 
metal surgical tray in the laminar flow hood in the aseptic lab to dry until ready for use. Repeated the procedure for the other coupon types, replacing the nitric acid solution and deionized water rinse between each step., ${ }^{2,3,13,15}$

Conducted high temperature oxidation at $594^{\circ} \mathrm{C}\left(1100^{\circ} \mathrm{F}\right)$ for 2 hours in a muffle furnace (Fisher Scientific Isotemp(B) after the passivation step. Allowed coupons to cool to room temperature. Stored in dry sterile container or immersed in $50 \mathrm{ppm}$ ionic silver solution as required. ${ }^{12,16}$

\section{F. Challenge Organisms}

The six challenge organisms used for this experiment were selected from a list of microorganisms previously recovered from spacecraft potable water or environmental control and life support systems. The challenge bacteria were either inoculated individually or in combination and include: Pseudomonas aeruginosa (ATCC 10145), Sphingomonas paucimobilis (ATCC 29837), Cupriavidus metallidurans (ATCC 43123), Methylobacterium fujisawaense (ATCC 43884), Burkholderia cepacia (ATCC 25416), and Wautersia basilensis (JSC strain 073130023-1). The challenge microorganisms were grown overnight in a suitable growth medium (in this case $10 \%$ or $3 \mathrm{~g} / \mathrm{L} \mathrm{TSB}$ ), washed in PBS to remove excess nutrients, and re-suspended in finished Nanopure water without biocide for addition to the bioreactor at a final volume and concentration of $1 \mathrm{~mL}$ at $1 \times 10^{8} \mathrm{CFU} / \mathrm{mL}$ per the standard test method.

\section{Results}

\section{A. HPC Results}

Continuous exposure to $0.4 \mathrm{mg} / \mathrm{L}(400 \mathrm{ppb}$ ) ionic silver over the course of 24 hours during the flow phase resulted in an average $>7-\log$ HPC reduction of bacterial cells over the control samples that were not exposed to any treatment (Figure 2). The residual effect of a 24-hour passivation treatment in $50 \mathrm{mg} / \mathrm{L}$ of ionic silver resulted in a $>3-\log$ reduction, whereas a two-week treatment resulted in a $>4-\log$ reduction. The antimicrobial efficacy was increased when the $50 \mathrm{mg} / \mathrm{L}$ silver passivation treatments were combined with exposure to the residual $0.4 \mathrm{mg} / \mathrm{L}$ ionic silver. However, the oxidation trial did not appear to cause an increase in antimicrobial efficacy for the metals used in this experimentation.

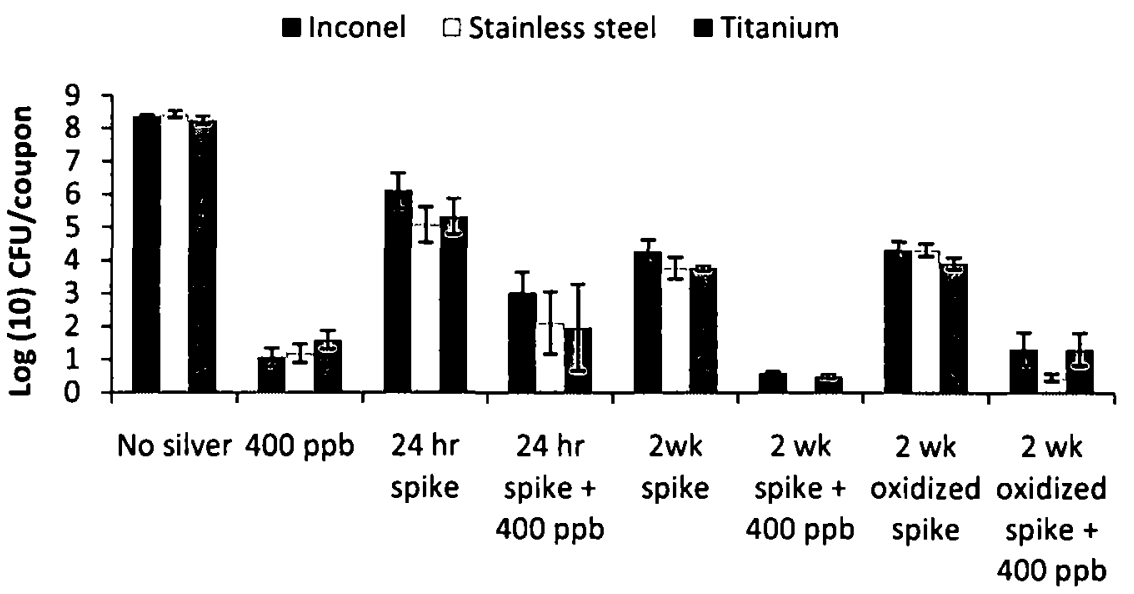

Figure 2. Reactor Coupon HPC Comparison $(n=8)$. 


\section{B. AODC Results}

The AODC fluorescent microscopy was performed to determine the mechanism of cellular degradation and for cellular enumeration. The ionic silver biocide samples showed a slight decrease over samples without any biocide present which indicated that the cells were present in the samples (Figure 3). However, the cells were not culturable which supports the theory that silver is an effective antimicrobial through multiple pathways. The data also indicated that when the cells were harvested for microscopy most were no longer viable, but their cellular membranes were still intact.

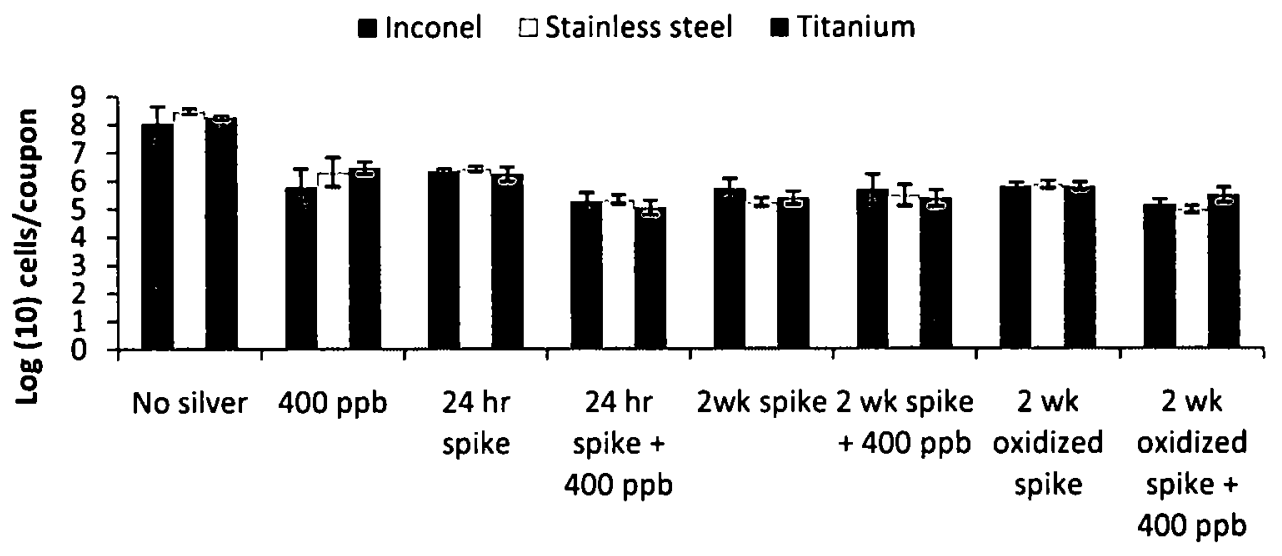

Figure 3. Reactor Coupon AODC Comparison ( $\mathrm{n}=\mathbf{8})$.

\section{ICP-OES Results}

The ICP-OES results indicated that coupon inoculum and CSTR feed concentrations were consistent and within the specified targets (Table 1). The CDC before results indicted that there were only trace amounts of silver detected in the reactor bulk process fluid during the batch mode. This indicated that most of the AgF that had plated out onto the metallic test surfaces during the silver passivation step remained adhered to them in the high shear environment. The feed and CDC bulk process fluid samples collected after the CSTR step indicated that there was only a very slight loss of ionic silver due to plating out on to test stand surface materials. This meant that the exposure to specific concentrations of ionic silver during the test was consistent and that the CDC biofilm reactor was a nominal test stand for this experimentation.

\section{Conclusions}

The CDC biofilm reactor performed nominally and was an adequate test stand for this series of experimentation. The processing of samples was supported and variance minimized by the use of a modified standard test method. There was minimal variation between and within each experiment based on the AODC, HPC, and ICP monitoring of the bulk processing fluid at the beginning and the end of each assay. The research team was able to achieve a fairly consistent and specific deposition of ionic silver on the metallic test surfaces and was able to slow the degradation of the adherence of that deposition. In addition, the loss of residual AgF due to plating during the CSTR mode was reduced to minimal levels. According to the HPC results, each advancement in the use of ionic silver provided an increase in microbial control. The only exception to that was the oxidation of the metals which did not achieve the desired results. One explanation for this is that due to the pitting of the surfaces during the oxidation step, crevices were created on the metal surfaces that allowed for slight increases in microbial attachment. However, this response was dependent upon the metal type as they did not all respond uniformly to the oxidation process. Overall, the results indicated that $0.4 \mathrm{mg} / \mathrm{L}$ ionic silver is an effective biocide against many bacteria and that a pre-passivation of metal surfaces with silver can provide additional microbial control. 
Table 1. ICP results

\begin{tabular}{|c|c|c|c|c|c|}
\hline Reactor & $\begin{array}{l}\text { Coupon } \\
\text { Inoculum } \\
\text { (ppm) }\end{array}$ & $\begin{array}{l}\text { Feed } \\
\text { Before } \\
\text { (ppb) }\end{array}$ & $\begin{array}{l}\text { CDC } \\
\text { Before } \\
\text { (ppb) }\end{array}$ & $\begin{array}{l}\text { Feed } \\
\text { After } \\
\text { (ppb) }\end{array}$ & $\begin{array}{l}\text { CDC } \\
\text { After } \\
\text { (ppb) }\end{array}$ \\
\hline No silver & N/A & N/A & N/A & $\mathrm{N} / \mathrm{A}$ & $\mathrm{N} / \mathrm{A}$ \\
\hline $400 \mathrm{ppb}$ & N/A & $393 \pm 4$ & $12 \pm 1$ & $384 \pm 1$ & $388 \pm 1$ \\
\hline 24 hr spike & $49.97 \pm 0.50$ & $\mathrm{~N} / \mathrm{A}$ & $17 \pm 1$ & N/A & ND \\
\hline $\begin{array}{r}24 \text { hr spike } \\
+400 \mathrm{ppb}\end{array}$ & $50.92 \pm 0.23$ & $556 \pm 1$ & $11 \pm 0$ & $371 \pm 5$ & $396 \pm 0$ \\
\hline 2wk spike & $49.97 \pm 0.50$ & N/A & $12 \pm 1$ & $\overline{\mathbf{N}} / \mathrm{A}$ & ND \\
\hline $\begin{aligned} & 2 \text { wk spike } \\
+ & 400 \mathrm{ppb}\end{aligned}$ & $50.92 \pm 0.23$ & $457 \pm 5$ & ND & $271 \pm 1$ & $277 \pm 2$ \\
\hline $\begin{array}{c}\text { wk } \\
\text { oxidized spike }\end{array}$ & $51.60 \pm 0.76$ & $\bar{N} / \mathrm{A}$ & ND & N/A & ND \\
\hline $\begin{array}{l}\text { wk } \\
\text { oxidized spike } \\
+400 \mathrm{ppb}\end{array}$ & $51.01 \pm 0.01$ & $\overline{449 \pm 9}$ & ND & $354 \pm 1$ & $371 \pm 5$ \\
\hline
\end{tabular}

\section{Acknowledgments}

The authors wish to express their sincere appreciation to John Catechis, Griffin Lunn, Megan Morford, and the NASA Life Science Services Contract (Dynamac Corp.)(NAS10-02001) for research support.

\section{References}

' ASTM Designation 2562-07: Standard Test Method for Quantification of Pseudomonas aeruginosa Grown with High Shear and Continuous Flow using a CDC Biofilm Reactor.

${ }^{2}$ ASTM Designation A 380 - 06: Standard Practice for Cleaning, Descaling, and Passivation of Stainless Steel Parts, Equipment, and Systems.

${ }^{3}$ ASTM Designation A 967 - 05: Standard Specification for Chemical Passivation Treatments for Stainless Steel Parts.

${ }^{4}$ Bloem, J., 1995, "Fluorescent staining of microbes for total direct counts," In Molecular Microbial Ecology Manual, Vol. 8, Kluwer Academic Publishers, Netherlands, 1995, pp. 1-12.

${ }^{5}$ Gupta, A., and Silver, S., "Silver as a biocide: will resistance become a problem?," Nature Biotechnology, Vol. 16, 1998, pp. 888.

${ }^{6}$ Hobbie, J.E., Daley, R.J., and Jasper, S., "Use of Nucleopore filters for counting bacteria by fluorescence microscopy," Applied Environmental Microbiology. Vol. 33, 1977, pp. 1225-1228.

${ }^{7}$ Hwang, M.G., Katayama, H., and Ohgaki, S., "Accumulation of copper and silver onto cell body and its effect on the inactivation of Pseudomonas aeruginosa," Water Science and Technology, Vol. 54, 2006, pp. 29-34.

${ }^{8}$ JSC PRC-5002 Rev. D: Process Specification for Passivation and Pickling of Metallic Materials.

${ }^{9}$ Mudgett, P.D., Flanagan, D.T., Schultz, J.R., and Sauer, R.L., "Depletion of biocidal iodine in a stainless steel water system," SAE Paper $941391,24^{\text {th }}$ International Conference on Environmental Systems, 1994.

${ }^{10}$ NASA. "Constellation Program Human-Systems Integration Requirements," CxP 70024, Baseline, 2007. (NASACxP-70024) 
${ }^{11}$ NASA. "Man-Systems Integration Standards," Revision B, July 1995. (NASA-STD-3000)

${ }^{12}$ Peterson, L., de Vera, J., Vega, L.M., Adam, N., Steele, J., Rector, T., and Gazda, D., "Crew Exploration Vehicle (CEV) Potable Water System Verification Coordination," 38th International Conference on Environmental Systems (ICES), San Francisco, CA, SAE Publication 2008-01-2083, 2008.

${ }^{13}$ Roberts, M.S., Hummerick, M. E., Edney, M. S. L., Bisbee, P.A., Loucks, S., Pickering, K.D., and Sager, J.C., "Assessment of silver based disinfection technology for CEV and future US spacecraft: Microbial Efficacy," 37th International Conference on Environmental Systems (ICES), Chicago, IL, SAE Publication 2007-01-3142, 2007.

${ }^{14}$ Rusin, P., K. Bright K, and C. Gerba. 2003. Rapid reduction of Legionella pneumophila on stainless steel with zeolite coatings containing silver and zinc ions. Lett Appl Microbiol. 36(2):69-72.

${ }^{15}$ SAE Standard AMS-2700B: Passivation of Corrosion Resistant Steels.

${ }^{16}$ Sauer, R.L., P.D. Mudgett, and J.R. Schultz. 2001. A technique for injecting $\mathrm{Ag}^{+}$ions as biocide into $\mathrm{H}_{2} \mathrm{O}$. NASA Tech Briefs. MSC-23170.

${ }^{17}$ Silver, S. 2003. Bacterial silver resistance: Molecular biology and use and misuses of silver compounds. FEMS Microbiology Reviews. 27:341-353. 